\title{
WEB-DL Endovascular Treatment of Wide-Neck Bifurcation Aneurysms: Long-Term Results in a European Series
}

\author{
L. Pierot, J. Klisch, DT. Liebig, J.-Y. Gauvrit, M. Leonardi, N.P. Nuzzi, F. Di Paola, V. Sychra, B. Mine, and B. Lubicz
}

\begin{abstract}
BACKGROUND AND PURPOSE: Flow disruption with the WEB-DL device has been used safely for the treatment of wide-neck bifurcation aneurysms. The stability of aneurysm occlusion after this treatment was evaluated in the short and midterm, but not in the long term. This retrospective multicenter European study is the continuation of an already published series dealing with short- and midterm anatomic results and analyzes long-term data in patients treated with the WEB-DL.
\end{abstract}

MATERIALS AND METHODS: Twelve European neurointerventional centers initially participated in the study. In addition to data collected for the initial publication, images obtained at long-term follow-up were collected and independently analyzed by the same experienced interventional neuroradiologist.

RESULTS: Of the initial 45 patients, 26 (20 women and 6 men; 35-73 years of age; mean, $55.2 \pm 10.6$ years; median, 55.5 years) with 26 aneurysms treated with the WEB-DL device had long-term follow-up (median, 27.4 months). Three of 26 patients (11.5\%) were retreated between short- and midterm follow-up, and none, between mid- and long-term follow-up. Long-term aneurysm occlusion in the 19 patients treated with the WEB only and not retreated during follow-up was complete occlusion in 13/19 patients (68.4\%), including aneurysms with opacification of the proximal recess in 9/19 patients (47.4\%), neck remnant in 3/19 patients (15.8\%), and aneurysm remnant in $3 / 19$ patients (15.8\%). In all patients (100.0\%), aneurysm occlusion was stable between midterm and long-term follow-up.

CONCLUSIONS: The results suggest that WEB treatment of wide-neck bifurcation aneurysms offers long-term stable occlusion.

ABBREVIATIONS: DL = Dual Layer; WEBCAST $=$ WEB Clinical Assessment of IntraSaccular Aneurysm Therapy

$\mathbf{E}$ ndovascular treatment is now the first-line treatment for both ruptured and unruptured intracranial aneurysms. ${ }^{1-4}$ However, the limitations of standard coiling have contributed to the development of new endovascular approaches, including balloon-assisted coiling, stent-assisted coiling, flow diversion, and flow disruption. ${ }^{5}$

Received February 20, 2015; accepted after revision April 15.

From the Department of Neuroradiology (L.P.), Hôpital Maison-Blanche, Université Reims-Champagne-Ardenne, Reims, France; Department of Diagnostic and Interventional Radiology and Neuroradiology (I.K., V.S.), Helios General Hospital, Erfurt, Germany; Department of Neuroradiology (T.L.), Universitätsklinikum Köln, Cologne, Germany; Department of Neuroradiology (I.-Y.G.), CHU Rennes, Rennes, France; Department of Neuroradiology (M.L.), Ospedale Bellaria, Bologna University, Bologna, Italy; Department of Neuroradiology (N.P.N.), Ospedale Galliera, Genova, Italy; Department of Neuroradiology (F.D.P.), Ospedale Santa Maria, Treviso, Italy; and Department of Neuroradiology (B.M., B.L.), Erasme University Hospital, Brussels, Belgium.

Please address correspondence to Laurent Pierot, MD, PhD, Service de Radiologie, Hôpital Maison-Blanche, 45, rue Cognacq-Jay, 51092 Reims cedex; e-mail: Ipierot@gmail.com

- Indicates open access to non-subscribers at www.ajnr.org

http://dx.doi.org/10.3174/ajnr.A4445
The WEB aneurysm embolization system (Sequent Medical, Aliso Viejo, California) is an intrasaccular device designed to disrupt the intra-aneurysmal flow at the level of the neck. ${ }^{6-9}$ Several devices are now available in the WEB family: WEBDual Layer (DL) and the more recently introduced WEB-Single Layer (SL) and WEB-Single Layer Sphere (SLS). ${ }^{10}$ Initial clinical experience and recent multicenter series have shown the clinical utility of this device in wide-neck bifurcation aneurysms with high technical success and low acute morbidity and mortality. ${ }^{7-11}$ Also, the initial WEB-DL literature suggested good efficacy with a high percentage of complete and adequate occlusion (complete occlusion or neck remnant) in the postoperative period and in the short-term follow-up. In the WEB Clinical Assessment of IntraSaccular Aneurysm Therapy (WEBCAST) trial, complete and adequate occlusion was observed in, respectively, $56.1 \%$ and $85.4 \%$ of aneurysms. ${ }^{11} \mathrm{~A}$ retrospective series evaluating both short- (median, 6 months) and midterm (median, 13 months) follow-up showed adequate occlusion in, respectively, $81.1 \%$ and $89.7 \%$ of aneu- 
rysms. ${ }^{12}$ Between short- and midterm follow-up, aneurysm occlusion was stable in $92.9 \%$ of aneurysms.

Aneurysm recanalization is an important issue in endovascular therapy, and wide-neck aneurysms (typical indications for the WEB) are highly prone to recanalization. ${ }^{13,14}$ Because the WEB is dedicated to the treatment of wide-neck bifurcation aneurysms, it is important to assess the long-term stability of aneurysm occlusion after WEB treatment. As a multicenter trial, the European study was already conducted in the first patients treated with the WEB; therefore, the decision was made to collect and analyze long-term follow-up in this series of patients when available. ${ }^{12}$ In this initial series, it was shown that opacification of the proximal recess was always stable at midterm and that it was equivalent to complete occlusion. ${ }^{12}$

\section{MATERIALS AND METHODS \\ Population}

The study received institutional review board approval, and according to the design of the trial, informed consent was waived. European neurointerventional centers selected for the previous series were contacted to inquire whether long-term anatomic follow-up was performed for their patients and whether they agreed to participate in this new analysis. Of the 12 European centers participating in the initial study, 10 had follow-up for some or all of their patients and agreed to participate.

\section{WEB-DL Device and Procedural Modalities}

The WEB-DL device and procedural modalities were previously presented in the initial article describing short- and midterm follow-up. ${ }^{12}$

\section{Data Collection}

As previously described, each center completed a patient file with the following data: patient age and sex, aneurysm status (ruptured/unruptured), aneurysm characteristics including location classified into 4 groups (ICA, MCA, posterior circulation, anterior communicating artery), size and neck size, date of the procedure, occurrence of complications during or after the procedure, use of additional devices during the procedure (coils, remodeling balloons, stents, or flow diverters), and the modified Rankin Scale score at discharge and at last follow-up. ${ }^{12}$

In complement to images already collected (pre- and postoperative, short-term, and midterm), long-term images were collected. Short-term follow-up was defined as the first follow-up performed $<8$ months after initial treatment. The second follow-up was defined as midterm follow-up, and the third followup, as long-term follow-up.

For digital subtraction angiography, frontal, lateral, and working views were collected as well as $3 \mathrm{D}$ angiography when available. For MR angiography and CT angiography, frontal, lateral, and working view reconstructions were collected. MRA or CTA examinations were used exclusively when DSA was not performed.

\section{Data Analysis}

To evaluate the anatomic results in a homogeneous population with typical indications for WEB-DL, we included patients if their aneurysms met precise criteria:
- Located at a bifurcation: ICA, MCA, anterior communicating artery, basilar artery, and PICA

- Nonthrombosed

- With a wide neck ( $\geq 4 \mathrm{~mm}$ )

- With a maximum diameter of $\leq 12 \mathrm{~mm}$.

The independent reader, who already analyzed the images (preand postoperative, short-term and midterm follow-up) for the initial series (J.-Y.G.), reviewed the long-term follow-up images. They were evaluated by using a 3-grade scale: complete occlusion (including complete occlusion with opacification of the proximal recess of the device), neck remnant, and aneurysm remnant. The reader also analyzed the evolution of aneurysm occlusion between mid- and long-term follow-up and classified it as improved, stable, or worsened.

Clinical data were already reviewed and analyzed by the 2 principal investigators of the study (B.L. and L.P.) for the initial series.

\section{RESULTS}

\section{Patient and Aneurysm Population}

The population of the initial series (midterm follow-up) was 45 patients. ${ }^{12}$ Among these 45 patients, 26 (20 women and 6 men; $35-73$ years of age; mean, $55.2 \pm 10.6$ years; median, 55.5 years) with 26 aneurysms treated with the WEB-DL device had longterm follow-up.

Aneurysm locations were the following: the MCA in 13 patients, posterior circulation in 9 patients (including 8 patients with basilar artery aneurysms and 1 with PICA aneurysm), anterior communicating artery in 3 patients, and ICA terminus in 1 patient. Two aneurysms were ruptured, and 24 were unruptured. Aneurysm size was 5.0-11.5 mm (mean, $7.8 \pm 1.6 \mathrm{~mm}$; median, $8.0 \mathrm{~mm}$ ). Neck size was $4.0-9.0 \mathrm{~mm}$ (mean, $5.7 \pm 1.4 \mathrm{~mm}$; median, $5.6 \mathrm{~mm}$ ).

\section{Treatment Modalities}

Treatment was conducted in a standard manner in 21 patients with 1 device deployed in the aneurysm. In 1 patient, 2 WEB-DL devices were deployed in the aneurysm due to the aneurysm shape. In 3 patients, stent placement was used as an additional treatment due to WEB-DL protrusion (2 patients) and to thromboembolic complication treated with abciximab and stent (1 patient). One patient had additional treatment with coils.

\section{Technical Issues, Complications, and Clinical Outcome}

Three thromboembolic complications were observed during the treatment. At last clinical follow-up, the mRS score was zero in 2 patients and 1 in 1 patient.

No intraoperative rupture was observed in this series.

Overall clinical outcome results at last clinical follow-up (6-28 months; mean, $13.8 \pm 5.6$ months; median, 13.0 months) were as follows: 24 patients with mRS 0 and 2 patients with mRS 1 (1 related to initial bleeding; 1, to a thromboembolic event). 

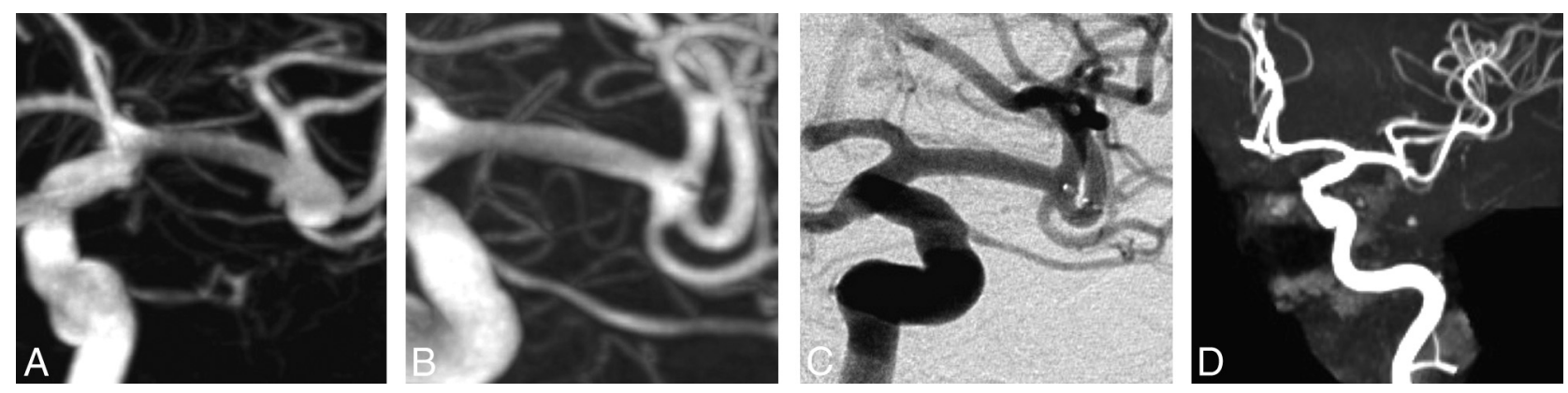

FIG 1. A, Preoperative DSA shows a wide-neck middle cerebral artery aneurysm with a daughter sac. $B$ and C, Three- and 12-month DSA show complete aneurysm occlusion. $D$, Twenty-seven-month MRA shows complete aneurysm occlusion.
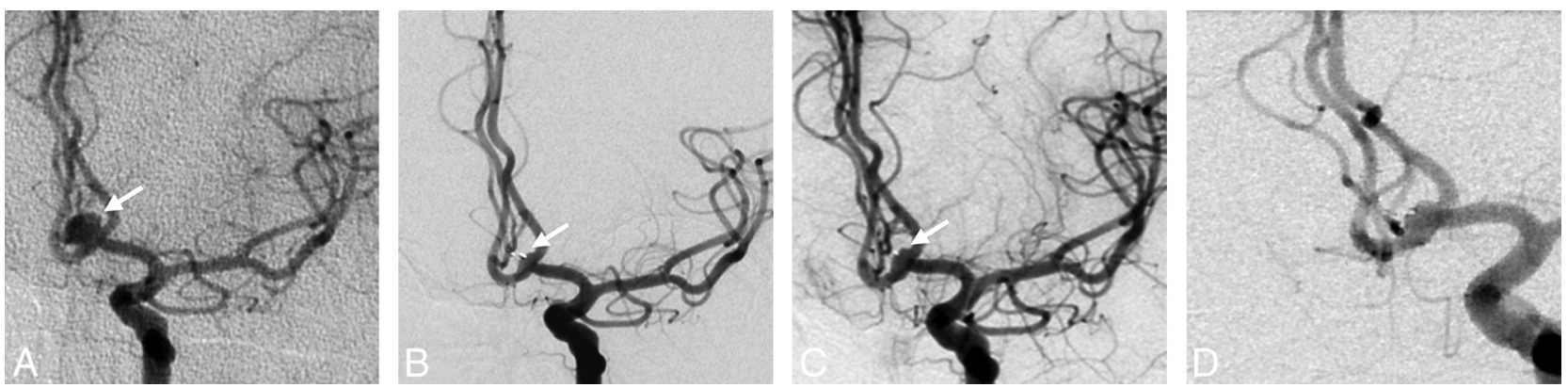

FIG 2. A, Preoperative DSA shows a wide-neck anterior communicating artery aneurysm. B-D, Six-, 12-, and 26-month DSA show stable complete aneurysm occlusion with opacification of the proximal recess.

\section{Retreatment}

Three of 26 patients $(11.5 \%)$ were retreated between shortand midterm follow-up. Two of these retreatments were planned according to aneurysm morphology and were part of the treatment strategy. Retreatment was performed with coils in 1 patient and coils + stent in 1 patient. One retreatment was unplanned, due to initial undersizing of the WEB, and was performed with coils.

No retreatment was performed between mid- and long-term follow-up.

\section{Short-Term Anatomic Outcome}

Because the goal of the study was to evaluate the quality and stability of aneurysm occlusion after WEB-DL treatment, the 4 patients with additional coiling and/or stent placement were not included in the evaluation. Finally $22 / 26$ patients $(84.6 \%)$ were evaluated in the short-term. Short-term follow-up was obtained from 2 to 8 months after the initial treatment (mean, $4.8 \pm 2.5$ months; median, 5 months). Modalities of shortterm follow-up were DSA in 19 patients, MRA in 2 patients, and CTA in 1 patient.

Complete aneurysm occlusion was obtained in 13/22 patients $(59.1 \%$ ) (Fig 1), including opacification of the proximal recess with complete occlusion of the aneurysm in 9/22 patients $(40.9 \%$ ) (Fig 2). Neck remnant was observed in 5/22 patients $(22.7 \%)$, and aneurysm remnant in $4 / 22$ patients $(18.2 \%)$. Adequate occlusion (complete occlusion or neck remnant) was observed in $18 / 22$ patients $(81.8 \%)$.

\section{Midterm Anatomic Outcome}

Because the goal of the study was to evaluate the quality and stability of aneurysm occlusion after WEB-DL treatment, 7 patients with additional coiling and/or stent placement during the initial procedure or retreatment were not included in the evaluation. One patient refused midterm follow-up examination. Finally $18 / 26$ patients $(69.2 \%)$ were evaluated in the midterm. Midterm follow-up was obtained from 8 to 28 months after the initial treatment (mean, $14.9 \pm 8.3$ months; median, 13.0 months). Modalities of midterm follow-up were DSA in 14 patients and MRA in 4 patients.

Complete aneurysm occlusion was obtained in 13/18 patients (72.2\%) (Fig 1), including opacification of the proximal recess with complete occlusion of the aneurysm in $9 / 18$ patients $(50.0 \%)$ (Fig 2). Neck remnant was observed in $3 / 18$ patients (16.7\%), and aneurysm remnant in $2 / 18$ patients $(11.1 \%)$. Adequate occlusion (complete occlusion, opacification of the proximal recess, or neck remnant) was observed in $16 / 18$ patients (88.9\%).

\section{Evolution between Short-Term and Midterm Follow-Up}

In $16 / 18$ patients $(88.9 \%)$, aneurysm occlusion was stable (Fig 1). In $2 / 18$ patients $(11.1 \%)$ with a neck remnant at 3 months, a worsening of the aneurysm occlusion was observed in midterm follow-up with aneurysm remnants in both cases. These 2 patients were not retreated and had no further worsening of aneurysm occlusion at long-term follow-up.

All patients with opacification of the proximal recess at shortterm follow-up had a stable aneurysm occlusion at midterm follow-up (Fig 2).

\section{Long-Term Anatomic Outcome}

Long-term follow-up was analyzed in 19 patients. The patient who refused the second (midterm) follow-up finally accepted the third follow-up. Seven patients with additional coiling and/or 

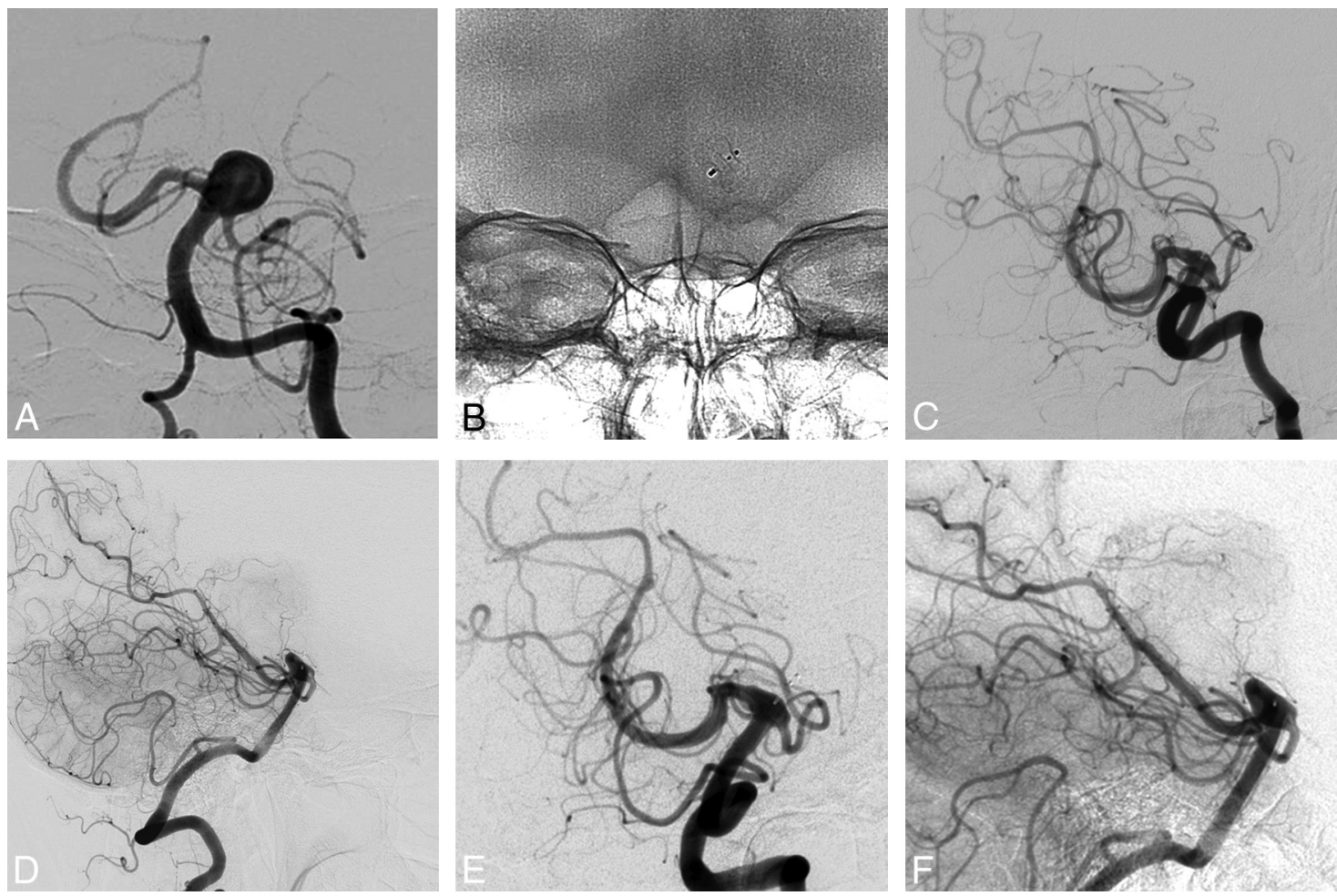

FIG 3. A, Preoperative DSA shows a wide-neck basilar artery aneurysm. $B$, The WEB device is deployed in the aneurysm. $C$ and $D$, Six-month DSA (oblique and lateral views) shows a small aneurysm remnant. $E$ and $F$, Twenty-one-month DSA (oblique and lateral views) shows that the aneurysm remnant has not grown.

stent placement during the initial procedure or retreatment were not included in the evaluation.

Long-term follow-up was obtained from 18 to 41 months after the initial treatment (mean, $27.9 \pm 13.7$ months; median, 26.0 months). Modalities of midterm follow-up were DSA in 6 patients, MRA in 9 patients, and CTA in 4 patients.

Complete aneurysm occlusion was obtained in 13/19 patients (68.4\%) (Fig 1), including opacification of the proximal recess with complete occlusion of the aneurysm in $9 / 19$ patients $(47.4 \%)$ (Fig 2). Neck remnant was observed in 3/19 patients (15.8\%), and aneurysm remnant in $3 / 19$ patients $(15.8 \%)$. Adequate occlusion (complete occlusion, opacification of the proximal recess, or neck remnant) was observed in $16 / 19$ patients $(84.2 \%)$.

\section{Evolution between Midterm and Long-Term Follow-Up}

In all patients (100.0\%), aneurysm occlusion was stable between midterm and long-term follow-up (Figs 1 and 2).

All patients with opacification of the proximal recess at midterm follow-up had a stable aneurysm occlusion at long-term follow-up; this result was equivalent to complete occlusion.

\section{DISCUSSION}

Precise evaluation of new endovascular techniques for intracranial aneurysm treatment is mandatory to determine their safety and efficacy compared with already established techniques. Efficacy has to be analyzed not only with short- and midterm anatomic results but also in longer follow-up.

The prospective good clinical practice studies (WEBCAST, French Observatory) conducted with the WEB have shown good safety of flow disruption in the treatment of wide-neck bifurca- tion aneurysms with no mortality and low morbidity. ${ }^{10,11}$ Shortterm (6 months) anatomic results were already reported in the WEBCAST study, showing complete occlusion in $56.1 \%$ of patients, neck remnant in $29.3 \%$, and aneurysm remnant in only $14.6 \%$. In the WEBCAST and French Observatory studies, evaluation of anatomic results will be performed at 1 year and then at 3 and 5 years.

Due to the issue of recanalization after endovascular treatment of aneurysms, WEB efficacy must be evaluated not only at short term but also at midterm and long term. It is singularly true for WEB treatment because its major indication is wide-neck bifurcation aneurysms, which are prone to recurrence. ${ }^{14}$ After the beginning of clinical experience with the WEB in 2010, it was important to have early and ongoing evaluation of aneurysm occlusion after WEB treatment. A retrospective analysis was conducted in 12 European centers in the first 45 patients treated with the WEB-DL. ${ }^{12}$ In this series, $4 / 45$ patients (8.9\%) were retreated within months following the initial WEB-DL treatment, 2 of these retreatments being planned according to aneurysm morphology and part of the treatment strategy. Short-term anatomic follow-up showed complete aneurysm occlusion in 21/37 patients $(56.8 \%)$ that includes aneurysms with opacification of the proximal recess in $12 / 37$ patients (32.4\%), neck remnant in 9/37 patients $(24.3 \%)$, and aneurysm remnant in $7 / 37$ patients $(18.9 \%)$. Midterm anatomic follow-up (median, 13 months) showed complete aneurysm occlusion in $20 / 29$ patients $(69.0 \%)$ that includes aneurysms with opacification of the proximal recess in $12 / 29$ patients $(41.4 \%)$, neck remnant in $6 / 29$ patients $(20.7 \%)$, and aneurysm remnant in $3 / 29$ patients (10.3\%). Aneurysm occlusion 
was stable between short- and midterm follow-up in $26 / 28$ patients $(92.9 \%)$. In $2 / 28$ patients $(7.1 \%)$ with neck remnants, a worsening of the aneurysm occlusion was observed in midterm follow-up, leading to aneurysm remnant in both cases. All patients with opacification of the proximal recess at short-term follow-up had a stable aneurysm occlusion at midterm follow-up, and this result was equivalent to complete occlusion.

Recently, a single center reported different results in a relatively small number of aneurysms. ${ }^{15}$ In this series that included 15 patients with 15 aneurysms consecutively treated with the WEB, aneurysm occlusion evaluated in 7 patients at midterm follow-up (median, 18.6 months) was complete occlusion in $0 / 7$ aneurysms $(0.0 \%)$, neck remnant in 4/7 (52.7\%), and aneurysm remnant in 3/7 (47.3\%). The reasons for the discrepancy between the study of Cognard and Januel $^{15}$ and the present series are multiple. One is probably related to the selection of aneurysms treated with the WEB. As indicated by Cognard and Januel, only very complicated wide-neck bifurcation aneurysms untreatable with other techniques were included in their series. Another factor is the treatment technique. As outlined during the initial experience with the WEB, sizing of the device is critical and undersizing of the device may be associated with poor anatomic results. It is difficult to know whether appropriate sizing was used in this series. However, the postoperative results were mostly neck and aneurysm remnants (respectively, 8/15 and 1/15), suggesting that WEB undersizing was accepted in some cases. All 15 patients were asymptomatic and were not retreated at follow-up; instead, they were controlled by ongoing angiography.

The present series evaluates the long-term follow-up (median, 27.4 months) of the patients of the previous series. Unfortunately, not all patients had long-term follow-up, and the same expert independently analyzed only 26 of them. The results are focused on patients treated exclusively with the WEB because the goal of the study was to analyze the anatomic stability after such treatment. At long-term follow-up, complete aneurysm occlusion was obtained in $13 / 19$ patients $(68.4 \%)$ that includes aneurysms with opacification of the proximal recess in $9 / 19$ patients $(47.4 \%)$, neck remnant in $3 / 19$ patients $(15.8 \%)$, and aneurysm remnant in $3 / 19$ patients $(15.8 \%)$. Adequate occlusion (complete occlusion, opacification of the proximal recess, or neck remnant) was observed in 16/19 patients $(84.2 \%)$. Aneurysm occlusion was stable in all patients between mid- and long-term follow-ups.

This series has several limitations. First, it is retrospective and has a limited number of patients, and long-term follow-up after treatment with the WEB only was evaluated in only 19 patients. Larger series are mandatory to precisely analyze longterm stability of aneurysm occlusion after WEB treatment. However, it is important to have a preliminary evaluation showing that there is no major instability of aneurysm occlusion in the long term. Some recent techniques were very little evaluated in the long term, for example, stent placement or flow diversion. A second limitation is that short- and midterm anatomic evaluations were conducted by using heterogeneous modalities (mostly DSA and MRA). However, recent publications confirm the value of MRA in the follow-up of intracranial aneurysms. ${ }^{16,17} \mathrm{~A}$ third limitation is that only WEB-DL (and not WEB-Single Layer and WEB-Single Layer Sphere) treatment was evaluated.

\section{CONCLUSIONS}

The present series shows that in this group of complex wideneck bifurcation aneurysms, appropriate occlusion was obtained in a high percentage of cases in the short- $(81.8 \%)$, mid(88.9\%), and long-term $(84.2 \%)$ follow-up. The results were overall quite stable. Only 2 patients $(11.1 \%)$ had progressed from neck remnant to aneurysm remnant at midterm followup, and there was no case of late recanalization. Most important, all aneurysms with opacification of the proximal recess at short-term follow-up had stable aneurysm occlusion at midand long-term follow-up.

Disclosures: Laurent Pierot-RELATED: Consulting Fee or Honorarium: Sequent; UNRELATED: Consultancy: Codman, Covidien/ev3, MicroVention, Neuravi. Joachim Klisch—RELATED: Consulting Fee or Honorarium: Sequent Medical*; UNRELATED: Consultancy: proctoring and consultancy for Sequent Medical.* Thomas LiebigRELATED: Consulting Fee or Honorarium: Sequent Medical, Germany (consulting and proctoring). Nunzio Paolo Nuzzi-UNRELATED: Consultancy: Sequent Medical, Covidien, Comments: fees received as a proctor. Boris Lubicz-UNRELATED: Consultancy: Codman, MicroVention. *Money paid to the institution.

\section{REFERENCES}

1. Molyneux A, Kerr R, Stratton I, et al; International Subarachnoid Aneurysm Trial (ISAT) Collaborative Group. International Subarachnoid Aneurysm Trial (ISAT) of neurosurgical clipping versus endovascular coiling in 2143 patients with ruptured intracranial aneurysms: a randomised trial. Lancet 2002;360:1267-74 CrossRef Medline

2. McDougall CG, Spetzler RF, Zabramski JM, et al. The Barrow Ruptured Aneurysm Trial. J Neurosurg 2012;116:135-44 CrossRef Medline

3. Cognard C, Pierot L, Anxionnat R, et al; Clarity Study Group. Results of embolization used as the first treatment choice in a consecutive nonselected population of ruptured aneurysms: clinical results of the Clarity GDC study. Neurosurgery 2011;69:837-41; discussion 842 CrossRef Medline

4. Pierot L, Spelle L, Vitry F; ATENA Investigators. Immediate clinical outcome of patients harboring unruptured intracranial aneurysms treated by endovascular approach: results of the ATENA study. Stroke 2008;39:2497-504 CrossRef Medline

5. Pierot L, Wakhloo A. Endovascular treatment of intracranial aneurysms: current status. Stroke 2013;44:2046-54 CrossRef Medline

6. Ding YH, Lewis DA, Kadirvel R, et al. The Woven EndoBridge: a new aneurysm occlusion device. AJNR Am J Neuroradiol 2011;32:607-11 CrossRef Medline

7. Pierot L, Liebig T, Sychra V, et al. Intrasaccular flow-disruption treatment of intracranial aneurysms: preliminary results of a multicenter clinical study. AJNR Am J Neuroradiol 2012;33:1232-38 CrossRef Medline

8. Lubicz B, Mine B, Collignon L, et al. WEB device for endovascular treatment of wide-necked bifurcation aneurysms. AJNR Am J Neuroradiol 2013;34:1209-14 CrossRef Medline

9. Pierot L, Klisch J, Cognard C, et al. Endovascular WEB flow disruption in middle cerebral artery aneurysms: preliminary feasibility, clinical, and anatomical results in a multicenter study. Neurosurgery 2013;73:27-34; discussion 34-35 CrossRef Medline

10. Pierot L, Moret J, Turjman F, et al. WEB treatment of intracranial aneurysms: feasibility, complications, and 1-month safety results with WEB DL and WEB SL/SLS in the French Observatory. AJNR Am J Neuroradiol 2015;36:922-27 CrossRef Medline

11. Pierot $\mathrm{L}$, Costalat $\mathrm{V}$, Moret $\mathrm{J}$, et al. Safety and efficacy of aneurysm treatment with WEB: results of WEBCAST study. J Neurosurg. In press

12. Lubicz B, Klisch J, Gauvrit JY, at al. WEB-DL endovascular treatment of wide-neck bifurcation aneurysms: short- and midterm re- 
sults in a European study. AJNR Am J Neuroradiol 2014;35:432-38 CrossRef Medline

13. Benaissa A, Barbe C, Pierot L. Analysis of recanalization after endovascular treatment of intracranial aneurysm (ARETA trial): presentation of a prospective multicenter study. J Neuroradiol 2015;42: 80-85 CrossRef Medline

14. Pierot L, Cognard C, Anxionnat R, et al; CLARITY Investigators. Endovascular treatment of ruptured intracranial aneurysms: factors affecting midterm quality anatomic results-analysis in a prospective multicenter series of patients (CLARITY). AJNR Am J Neuroradiol 2012;33:1475-80 CrossRef Medline
15. Cognard C, Januel AC. Remnants and recurrences after the use of the WEB intrasaccular device in large-neck bifurcation aneurysms. Neurosurgery 2015;76:522-30; discussion 530 CrossRef Medline

16. Pierot L, Portefaix C, Gauvrit JY, et al. Follow-up of coiled intracranial aneurysms: comparison of 3D time-of-flight MR angiography at $3 \mathrm{~T}$ and $1.5 \mathrm{~T}$ in a large prospective series. AJNR Am J Neuroradiol 2012;33:2162-66 CrossRef Medline

17. Pierot L, Portefaix C, Boulin A, et al. Follow-up of coiled intracranial aneurysms: comparison of 3D time-of-flight and contrast-enhanced magnetic resonance angiography at $3 \mathrm{~T}$ in a large, prospective series. Eur Radiol 2012;22:2255-63 CrossRef Medline 
T he authors apologize and state that in the original article "WEB-DL Endovascular Treatment of Wide-Neck Bifurcation Aneurysms: Long-Term Results in a European Study” by L. Pierot, J. Klisch, T. Liebig, J.-Y. Gauvrit, M. Leonardi, N.P. Nuzzi, F. Di Paola, V. Sychra, B. Mine, and B. Lubicz [AJNR Am J Neuroradiol 2015;36:2314-19, 10.3174/ajnr.A4445], there is an error in the author affiliations of Prof. M. Leonardi (M.L.). The correct version is given below.

Department of Neuroradiology (M.L.), Ospedale Bellaria, IRCCS Istituto delle Scienze Neurologiche di Bologna and DIMES, Bologna University, Bologna, Italy.

http://dx.doi.org/10.3174/ajnr.A4643 